\title{
Anthrax in the United States
}

\author{
By JAMES H. STEELE, D.V.M., M.P.H., an d RAYMOND J. HELVIG, D.V.M., M.P.H.
}

$\mathrm{A}^{\mathrm{N} T}$ NTHRAX TODAY does not seem to present the serious public health problem of former years. In 1951, only 60 cases were reported to the National Office of Vital Statistics, Public Health Service. Forty-five, or 75 percent, of these cases occurred in the northeastern States and were attributed to occupational exposure. There were less than 15 human cases in uther States. The highest incidence occurred in January, February, March, April, May, and November. During the period 1945 to 1951 , inclusive, 372 cases of human anthrax occurred, most of them in the 7 northeastern States, where industrial exposure is usually stated to be the source of infection (table 1). In the remaining 41 States, 63 cases were reported, of which 29 (21 farmers and 8 veterinarians) were due to agricultural exposure. Twenty States reported no cases of anthrax in the period 194551 ; 24 reported less than 10 cases; 1 , less than 25; 2, less than 100; and 1, more than 100.

The 5 cases reported in Florida were attributed to an outbreak of bovine anthrax in the fall of 1951. The individuals involved were a cowboy who skinned a cow, dead of anthrax, two veterinarians who vaccinated cattle in this area, a laboratory technician who handled a suspected specimen, and a child in a nearby town. In Arkansas 5 of 9 cases were associated with the skinning of a cow that had died suddenly. The farmer was assisted by his family and neighbors in the salvage operation. The 2 cases

Dr. Steele is chief, veterinary public health section, Communicable Disease Center, Public Health Serv. ice, Atlanta, Ga.; Dr. Helvig is assistant chief, milk and food branch, Division of Sanitation, Bureau of State Services. reported in Kentucky were in farmers who removed the hides from mules that had died of anthrax. The mule carcasses then were fed to swine, and the swine developed anthrax. In California, one of the cases occurred in a sheepherder who sheared infected sheep. On different occasions, three California veterinarians contracted the disease while performing post mortems on a cow, dead of anthrax. In New Jersey, a farmer who killed and dressed an infected heifer developed the disease. Most of the human cases reported in the western and southern States occurred under similar conditions. All of the cases were of the cutaneous type. There are no records of human anthrax caused by the ingestion of contaminated milk or meat in the United States in recent years.

During 1952 provisional reports indicated that there were 42 human cases of anthrax in the United States. This compares with 60 in 1951. Three of the 1952 cases occurred in Ohio : in a veterinarian, a laboratory technician who handled specimens, and a carpenter who worked in a feed mill where contaminated feed had been handled.

\section{Animal Anthrax}

During the period 1945 to 1950 , inclusive, 658 outbreaks of animal anthrax were reported from 32 States with estimated losses of 8,504 head of livestock. Occurrences in new areas were reported from 51 counties in 16 States. In 1951, a noticeable increase in outbreaks was observed. There were 483 outbreaks in 25 States involving 113 counties, with a loss of 2,753 animals. Three-fourths as many outbreaks occurred in 1951 as in the 6-year period 1945-50; however, the total number of animal losses was 
Table 1. Reported cases of human anthrax: United States and each State, 1945-51

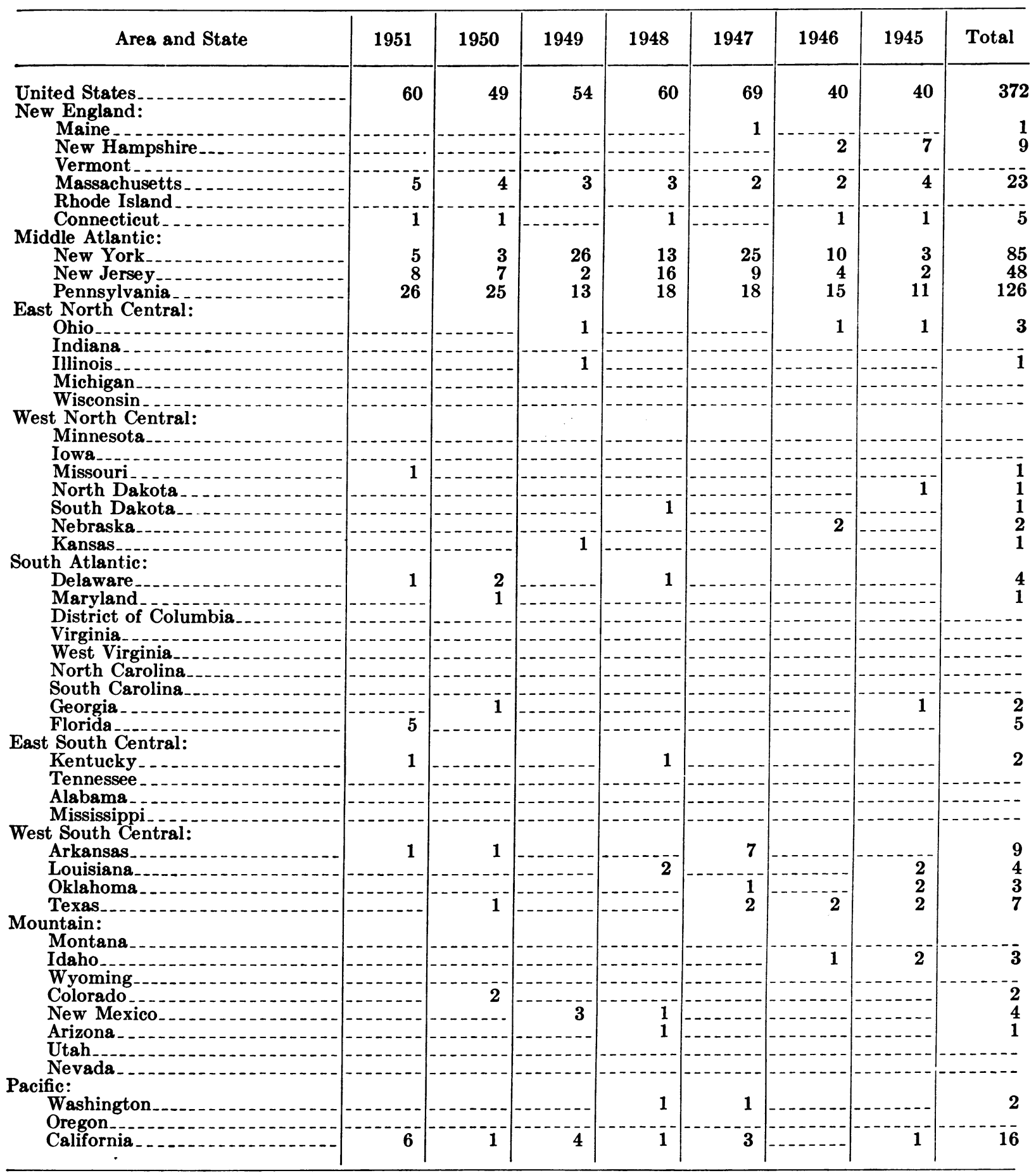

less than in 1946 when there was a severe epizootic in Louisiana which killed over 3,000 animals. Missouri had the highest losses in 1951, with 694 animal deaths, of which 440 were in horses and mules. Fairly large losses were re- ported in California, Florida, Illinois, Iowa, Kentucky, Nevada, Tennessee, and Texas.

An unusual feature in the 1951 losses was the great number of widely scattered outbreaks in swine. The Bureau of Animal Industry, U. S. 
Department of Agriculture, reported 1,088 swine deaths compared to 1,001 deaths in cattle. The greatest swine losses were in Illinois, Iowa, Missouri, and Kentucky. Coincident with the increased number of swine cases was the condemnation of 232 infected carcasses by the Federal Meat Inspection Service. These 232 cases were more than half the total of 367 hogs and 39 cattle condemned because of anthrax during the entire period July 1945 through December 1951 in establishments under the supervision of the inspection service.

In 1951, outbreaks in animals were reported in 15 States, in 51 counties which previously had had no history of the disease: Indiana, Kentucky, Mississippi, New Jersey, and Ohio, 1 each ; Florida, Minnesota, and Oklahoma, 2 each; Louisiana, Tennessee, and Wisconsin, 3 each ; Missouri, 4 ; Texas, 6 ; Illinois, 10 ; and Iowa, 11. No human cases were attributed to any of the swine outbreaks. Wisconsin also reported 102 cases in mink. These were thought to have been caused by ingestion of infected animal feed.

The Florida outbreak was the first since 1928. The disease involved deer, and beef and dairy cattle. The cause was not determined. Bonemeal was suspected, but laboratory examination did not reveal Bacillus anthracis.

Although swine are considered to be more resistant to anthrax than any other livestock species, the disease is not uncommon in these animals in the areas where the infection exists enzootically. Infections in swine have also oc-

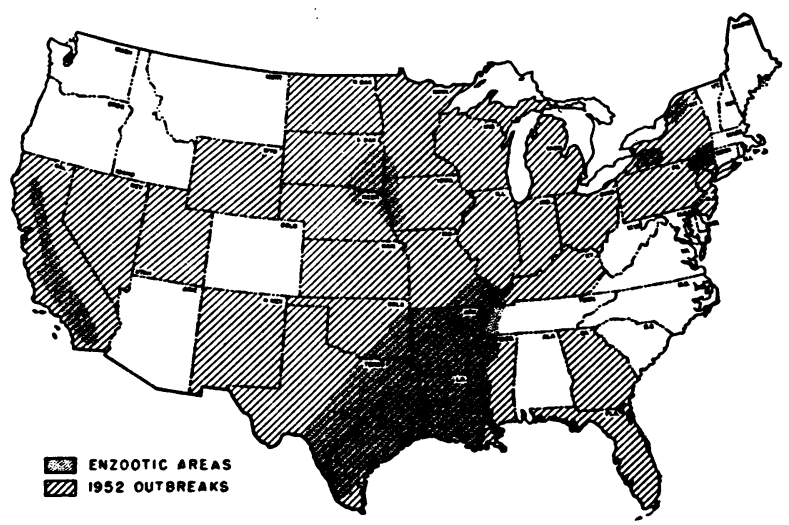

Anthrax in cattle, swine, horses, sheep, and mink.

Source: Bureau of Animal Industry, U. S. Department of Agriculture, and Public Health Service. curred in noninfected areas because of consumption of contaminated feed, but cases usually appear after infection of other livestock. Infection in swine usually results from their feeding on carcasses of animals dead of anthrax, from following infected animals, or from deep rooting in contaminated pastures during warm weather. Anthrax in swine may take many forms including the acute or the chronic forms with characteristic symptoms of septicemia or glossitis with enlargement of the cervical lymph nodes. In addition, mild or latent cases often occur which are not readily diagnosed. The swine outbreaks that occurred in the midwest in 1951 were all on premises hitherto considered free from infection and far removed from enzootic areas. Although the Bureau of Animal Industry, in cooperation with State livestock sanitary authorities, carried on special investigations, they failed to establish a definite source of infection. The history of some cases suggested that contaminated mixed feed may have been the source of infection. Laboratory examination of suspected feed samples failed to reveal $B$. anthracis.

The map illustrates the prevalence of anthrax in cattle, swine, horses, sheep, and mink in 1952. The stippled areas are the known enzootic areas. These areas were not involved in the swine outbreaks. Twenty States did not report any animal anthrax. The largest number of cases was reported in swine in the midwestern States (table 2) during the winter and early spring. This unusual seasonal occurrence is of special significance, inasmuch as anthrax is usually considered a warm weather disease among animals. Ohio had outbreaks in 56 counties involving over 280 farms. Indiana reported cases in 46 counties on 106 farms. Illinois reported 50 counties and 117 farms with anthrax cases. Michigan had 17 counties and 31 farms with infection. Wisconsin reported anthrax in 17 counties on 35 farms. All of these States reported the isolation of $B$. anthracis from bonemeal and attributed most of their outbreaks to contaminated bonemeal. It is important to observe that none of these States is considered to be an anthrax enzootic area. Previous to the outbreaks of late 1951 and early 1952, anthrax had not been reported in Indiana and Ohio for more than 20 years. Illinois and Wisconsin 
Table 2. Anthrax outbreaks, 1951-52

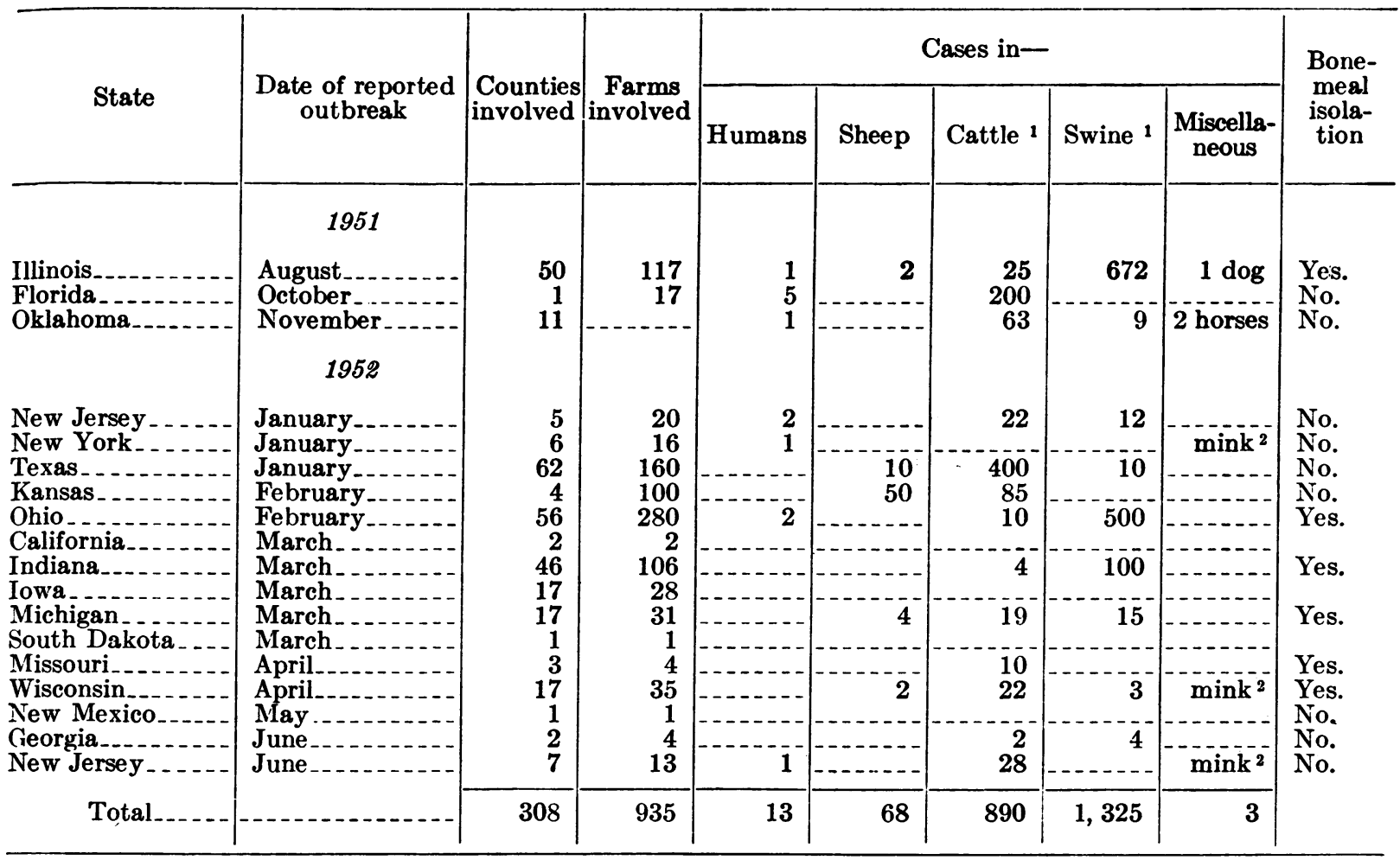

1 Estimated.

had not had any cases for years, and Michigan had not had a case since 1916. Dr. H. J. Stafseth, Michigan State College, states in a personal communication that the 1916 case is the only known diagnosed case up to 1952. The outbreaks in Ohio, Indiana, and Illinois mainly involved swine, while those in Wisconsin and Michigan were mainly on dairy farms. Wisconsin also had additional cases in mink, as did New Jersey and New York.

Kansas reported bovine anthrax in February. In April, anthrax was reported in beef and dairy cattle on more than $\mathbf{1 0 0}$ farms. An investigation revealed that anthrax had occurred only in herds that had been vaccinated with bacterin. The incubation period was from 3 to 120 days.

In 1952, Georgia reported the first outbreak of anthrax in animals since prior to 1945 . Bonemeal was suspected as the vehicle of infection but this was not proved.

Florida had a reoccurrence of anthrax in the summer of 1952 in the area where the 1951 outbreak was reported, and the 1952 outbreak spread to noninfected areas. Anthrax following vaccination with a bacterin was also reported. Of 300 beef cattle vaccinated by a rancher, 15 developed symptoms of anthrax 4 to 8 weeks following inoculation; 7 died, 2 of them after the surviving affected animals were treated with 3 million units of penicillin daily. None of the 15 animals exhibited typical symptoms and at first the cattle were thought to have been bitten by a snake. An extensive swelling was noted around the site of inoculation behind the shoulder, which in some cases extended forward to the brisket and back to the udder. The course of disease extended over a number of days.

The Ohio swine outbreaks which began in February 1952 were studied by the Ohio Division of Animal Industry and the Ohio Department of Health. These investigations were the first to reveal that imported raw bonemeal was contaminated with $B$. anthracis. Illinois, Michigan, Indiana, Wisconsin, and Missouri reported isolation of anthrax spores from bonemeal samples. The bonemeal was traced to a 
New York importer who had bought it in Belgium. Further investigation revealed that the bonemeal had been collected in Asia and southern Europe and brought to Belgium for reshipment to the United States and subsequent distribution in the midwest.

It is interesting to observe that nearly all the hogs involved were pregnant or nursing sows. This is readily explained by the fact that they were the only animals receiving a high proteincalcium ration which is recommended for the pregnant or nursing animal. Few or no cases were observed among other animals, except where some of the sow supplement ration was fed to other animals by mistake, or where through their own efforts, the animals were able to reach it.

The U. S. Department of Agriculture has adopted regulations prohibiting the importation of raw bonemeal. All bonemeal entering this country must now be sterilized at a temperature of $250^{\circ} \mathbf{F}$. under 20 pounds of pressure. In addition, many States have adopted similar regulations.

One of the important observations made in the Ohio outbreak was that penicillin or other antibiotics are to be preferred to immunizing agents in the control of anthrax in swine. The administration of 6 million units of penicillin in oil proved very effective in the large sows which weighed from 200 to 400 pounds or more. Penicillin has been used successfully in the treatment of cattle also but is not recommended as a control measure in place of vaccination. In

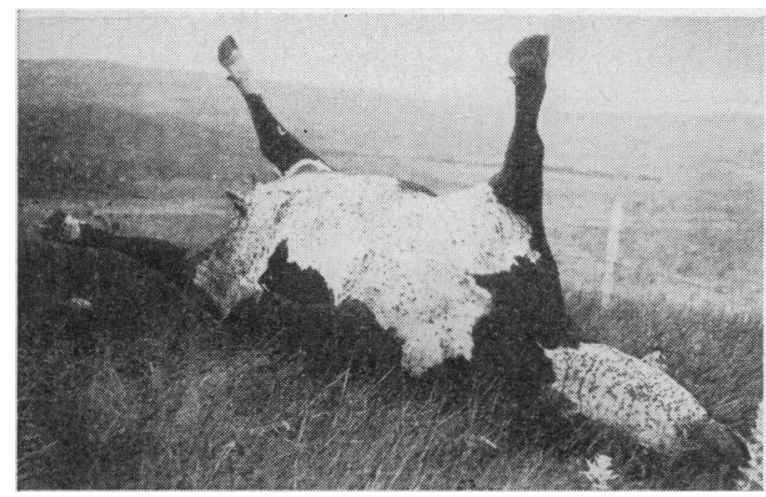

A cow dead of anthrax. Note the great number of flies on the carcass. Virulent anthrax germs were found in flies taken from this and a partly incinerated carcass on the same ranch. some bovine cases there have been relapses following the injection of penicillin. Aureomycin and terramycin were used with success.

\section{Public Health}

Even though anthrax is not readily transmitted to man, the numerous outbreaks of the disease in animals during the past 2 years have raised a number of public health questions. These questions include: What measures should be taken in handling milk from infected premises? How should meat animals from known infected farms be processed? What steps can be taken to prevent occupational disease among animal handlers? What procedures are recommended for animal disease control so as to remove any threat to public health?

\section{Milk}

The question of what to do with milk from a farm where anthrax has occurred in a milking herd or in other animals cannot be answered in all cases by a decision to quarantine the premises, but requires an examination of the problem at hand. As previously stated, there are no reports in the United States of the transmission of anthrax in milk to man. The results of unduly stringent quarantine regulations may tend to discourage reporting of anthrax, and such procedures may also present a serious economic problem to the dairyman. Some sizable nuisance problems have been known to develop when the milk from 500 or 600 cows was dumped on a farm in a warm climate.

The following recommendations have been formulated by the Public Health Service, with the assistance of the Bureau of Animal Industry of the U.S. Department of Agriculture, the Federal Food and Drug Administration, the Federal Civil Defense Administration, U. S. Livestock Sanitary Association, and the American Veterinary Medical Association.

The recommendations, which appear on pages 621 and 622, were transmitted February 4, 1953, by the Public Health Service to State and Territorial milk control authorities and others concerned. In forwarding these recommendations, Dr. Otis L. Anderson, chief of the Burea a of State Services, said :

"In the preparation of this material we have 


\section{One method of disposing of an anthrax-infected carcass by incineration}

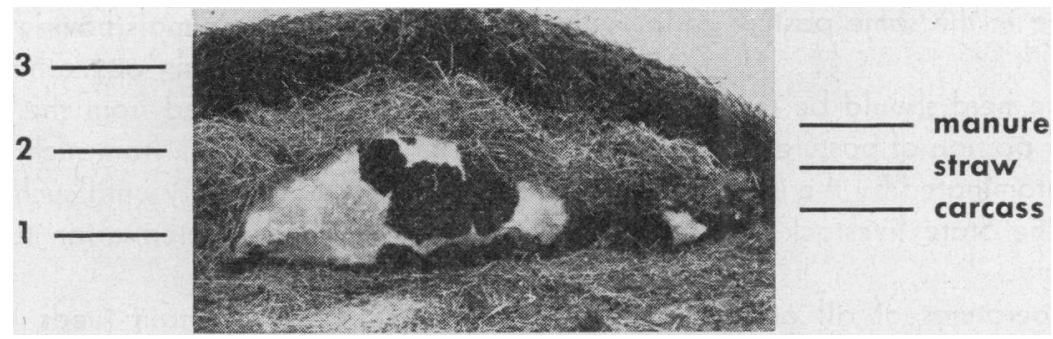

1. Saturate carcass with kerosene, crank case oil, or any other inflammable oil.

2. Cover carcass with a hayrack-full of straw.

3. Place two loads of heavy manure on top of the straw. Set afire. Add manure daily, or when necessary, to keep carcass covered until it is burned to a white ash.

attempted to be objective, realizing that: $(a)$ there are no supported records in the literature of anthrax being transmitted to man through the consumption of milk; (b) unduly stringent quarantining measures may tend to discourage reporting of anthrax thus nullifying control procedures; and (c) quarantining of dairy farms and exclusion of the entire milk supply from the market when a case occurs, may present a serious economic problem for the dairyman."

\section{Anthrax Control Recommendations}

1. All cases of anthrax, or suspected anthrax, should be reported by the dairyman to the local veterinarian and the health officer immediately, and such animals should be isolated completely from the herd and no milk from them sold until declared by a licensed veterinarian to be free from anthrax.

2. Where anthrax has occurred in the dairy herd and the animal or animals affected were stabled in the dairy barn:

a. All feed, hay, straw, manure and dirt likely to have been contaminated, the carcass of each animal dead from anthrax, and milk suspected of containing anthrax organisms or spores, should be disposed of promptly by complete burning or by deep (at least 6 feet) burial, under the direction or supervision of the State health department and/or the State livestock sanitary officials; the dust should be removed from the walls and ceilings; and the entire barn, including walls, ceilings, windows, floors, feed troughs, brooms, shovels, forks, spreaders, etc., should be thoroughly cleaned by washing with a 5-percent lye solution which should be left in contact with surfaces for at least 8 hours.

b. The temperatures of the remaining animals in the milking herd should be taken, immediately prior to each milking, by a veterinarian or some other official person designated by the health officer to take such temperatures, for a period of 10 days following the removal or recovery of the last case of anthrax. The records of such temperatures should be available at all times for examination by the health officer, livestock sanitary officials, and others concerned. All animals having a temperature of $103^{\circ} \mathrm{F}$. (cattle in hot, humid climates often have body temperatures of $103^{\circ} \mathrm{F}$. without having any infection; in this case a recheck of the temperature in the late evening or early morning, would be indicated) or showing any other evidence of disease should be isolated from the milking herd immediately, and no milk from such animal should be mixed with the market milk supply until such suspects are declared by a licensed veterinarian to show no further evidence of disease.

c. The milk utensils which have been exposed to any secretion or excretion from the anthrax infected animal should be submerged in boiling water for a period of at least 30 minutes as soon as possible after contamination. This should be done under the supervision of the State or local health department, or the State livestock sanitary officials. 
3. Where anthrax has occurred in any animal which has been in the same pasture or lot with the dairy cattle:

a. The entire herd should be removed from such lot, pasture, or portion of pasture, which is likely to have been contaminated by the infected animal, for such time as the State livestock sanitary authority deems necessary.

b. The temperatures of all of the cattle in the milking herd should be taken, immediately prior to each milking, by a veterinarian, or some other official person designated by the health officer to take such temperatures, for a period of 10 days following the removal or recovery of the last case of anthrax. The records of such temperatures should be available at all times for examination by the health officer and others concerned. All animals having a temperature of over $103^{\circ} \mathrm{F}$. or showing any other evidence of disease, should be isolated from the milking herd immediately, and no milk from such animal mixed with the market milk supply until such suspects are declared by a licensed veterinarian to show no further evidence of disease.

4. Where anthrax has occurred in any animal on the dairy farm, but has been completely separated from the dairy herd; or where anthrax has occurred on adjoining farms:

a. The dairy herd should be kept under close observation for a period of at least 10 days and any evidence of anthrax reported immediately to the health officer and the local veterinarian.

5. Where dairy cattle are vaccinated for anthrax:

a. Such preventive vaccination should be done in a manner and with a product which is approved by the State livestock sanitary authority.

b. The temperatures of all animals vaccinated against anthrax should be taken, immediately prior to each milking, by a veterinarian or some other official person designated by the health officer to take such temperatures, for a period of 10 days following vaccination or presence of anthrax infection on the premises. The records of such temperatures should be available at all times for examination by the health officer and others concerned. All animals having a temperature of over $103^{\circ} \mathrm{F}$. or showing any other evidence of disease, should be isolated from the milking herd immediately, and no milk from such animal mixed with the market milk supply until such suspects are declared by a licensed veterinarian to show no further evidence of disease.

6. Where certain feeds are suspected by the State officials as being contaminated with anthrax organisms, such feed should be embargoed, or otherwise isolated from further use and distribution pending resolution of the doubts concerning the safety of the product. If found to be contaminated with anthrax organisms it either should be rendered free from contamination by a method acceptable to the State livestock sanitary authority, or it should be destroyed in accordance with $2 a$ above. These determinations should be made as quickly as possible to reduce to a minimum, the physical and economic problems involved in embargoes.

It is realized that the livestock sanitary authorities in some States issue a quarantine that bars the movement of all animal products from the premises on which infection with anthrax has occurred, as a precautionary measure against the mechanical transmission of the disease from one premise to another. Therefore, it is imperative that the milk control authorities cooperate with the livestock sanitary authorities of the State concerned.

It is also important that local and State milk control officials, and the State and local livestock disease control officials, maintain close liaison with each other with regard to reporting of anthrax cases and anthrax control measures. This is necessary to provide for the maximum protection of the health of the persons who may have come in contact with infected animals on the farm, as well as for the protection of the milk consumer, and for the economic welfare of the dairy farmer. Persons handling anthrax infected animals, or materials, should be protected by rubber gloves and bects, which can subsequently be decontaminated with chemical disinfectants.

\section{Other Control Measures}

Processing meat animals from infected or quarantined farms should be done in abattoirs or packing plants that are under the supervision of the Federal Meat Inspection Service or a local meat inspection service where a trained veterinary inspector is on duty. Although the transmission to man of anthrax in meat has never been reported in the United States, the foreign literature has carried numerous reports. 
These reports have usually involved raw or semiraw meat products such as hard sausage.

Prevention of occupational anthrax among animal handlers can best be accomplished by health education. The farmer or animal handler must be cautioned against the treatment of sick animals and against attempts to salvage the hide of dead animals. The fact that no human cases occurred among farmers in Ohio can be explained by the farmer's practice of not making any effort to salvage a hog but of burying or burning it. He will skin a cow or horse and feed the carcass to the hogs. However, with the increasing availability of rendering plant pickups of dead animals, this latter practice is disappearing.

On a farm where anthrax is known to be present, the operator should receive instructions either from the attending veterinarian or the health department about how to protect his health. The most important thing to stress is personal hygiene and prompt medical care for any scratches, abrasions, or pimples that may appear.

Animal disease control is primarily the responsibility of the attending veterinarian and the livestock sanitary officials. The success of antibiotics in the treatment of animal anthrax has provided an excellent weapon to deal with this problem. The live spore vaccines have been used extensively in this country with good results, although sometimes they fail. They should be used only on premises where infection has been proved or where there is strong evidence of disease. The antibiotics may replace the antiserum and bacterins that previously have been used in herds or droves adjacent to infected premises.

\section{Conclusions}

Anthrax is not readily transmitted to man. In the United States there is no report of its transmission to man by meat or milk. During 1951-52 animal anthrax cases increased, especially among swine. Some of these outbreaks were traced to contaminated bonemeal. However, even though there were more animal cases, the human cases continued to decline, and in 1952 numbered less than in 1951. Public health aspects are discussed as they relate to milk, meat, occupational disease, and animal disease control.

\section{Anthrax Epidemic Curbed In Paraguay}

\begin{abstract}
Anthrax was temporarily halted in the countryside surrounding Coronel Oviedo, a town in Paraguay, after a 2-week fight this spring to prevent the spread of the virulent disease to 113,000 beef cattle. More than 1,300 cattle were given antianthrax vaccine. A quarantine area for the infected animals was established.

Barricades were erected on roads leading to Coronel Oviedo, and livestock growers taking their cattle to town either submitted them for vaccination or were required to return the animals to their properties. Even cart-drawing oxen were submitted to vaccination. Any slaughtered animals taken to the town for the market were examined by veterinarians for signs of disease.
\end{abstract}

Eighty head of cattle had died, but no hurwan cases of anthrax had been found, as of April 17, 1953. Anthrax is greatly feared in Parag::ay since livestock production is the backbone of the economy and beef cattle total almost 4 aninıals to each of the country's $1,500,000$ population, according to the news report released in April by the Institute of Inter-American Affairs.

The discovery of the sudden death of $\mathbf{4 0}$ eattle in Coronel Oviedo on March 14, 1953, brought immediate assistance to the area from the Technical Cooperation Administration offices located 87 miles away in Asuncion. Laboratory analysis of the ear of a dead animal confirmed the outbreak of anthrax, the first for the area in recent years. 